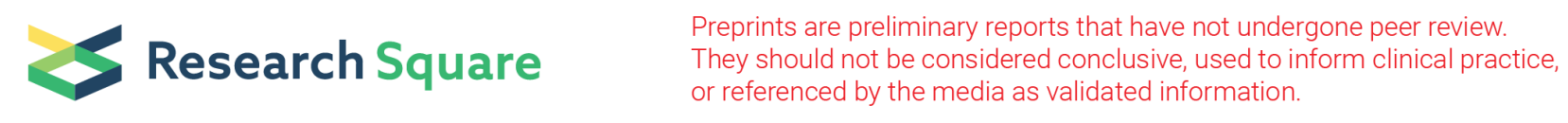

\title{
A structural equation modeling approach to understanding physical function of terminal cancer patients
}

\author{
Han-Gyo Choi \\ Catholic University of Korea \\ Hye-Ah Yeom ( $\nabla$ yha@catholic.ac.kr) \\ Catholic University of Korea \\ Myung Ah Lee \\ Seoul Saint Mary's Hospital \\ Jeong-Ran Ra \\ Seoul Saint Mary's Hospital
}

\section{Research Article}

Keywords: Terminal cancer, Physical function, Activities of daily living, Structural equation modeling, Pain, Fatigue

Posted Date: March 11th, 2021

DOI: https://doi.org/10.21203/rs.3.rs-160704/v1

License: (c) (1) This work is licensed under a Creative Commons Attribution 4.0 International License. Read Full License

Version of Record: A version of this preprint was published at Supportive Care in Cancer on August 26th, 2021. See the published version at https://doi.org/10.1007/s00520-021-06444-x. 


\section{Abstract}

Purpose Understanding the activities of daily living ( $A D L)$ of cancer patients at the end-of-life stage may help healthcare providers develop interventions for preserving physical function and enhance patient's dignity in an everyday care context. This study aims to develop and test a causal effect model of physical function in terminal cancer patients.

Methods A total of 238 terminal cancer patients were recruited from two hospitals in South Korea. The data were collected using a structured questionnaire including demographics, visual analogue scale for pain, Functional Assessment of Chronic Illness Therapy-Fatigue, and Katz index of independence in ADL. The collected data were analyzed using SPSS WIN 25.0 and AMOS 23.0 programs for structural equation modeling procedures.

Results The model showed a good fit to the data $\left(\chi^{2} / \mathrm{df}=2.08, \mathrm{GFI}=0.932, \mathrm{NFI}=0.966, \mathrm{TLI}=0.971, \mathrm{CFI}=0.982, \mathrm{AGFI}=0.874\right.$, RMSEA $=0.067$ ). Physical function of patients with terminal cancer was positively influenced by regular exercise and negatively influenced by hospitalization, fatigue, and pain, explaining $35.1 \%$ of the variance. In this study, regular exercise improved participants' ADL level directly and indirectly either by reducing fatigue or decreasing fatigue through controlling pain. Pain did not affect $A D L$ directly but decreased $A D L$ level indirectly through fatigue as a mediator.

Conclusion Based on these results, in order to minimizing the problems of physical function in terminal cancer patients, interventions that reduce pain and fatigue and provide regular exercise are required. Particularly, hospitalized patients are susceptible to a decrease in physical function, so regular physical function evaluations may be considered.

\section{Introduction}

The five-year survival rate of cancer patients was about $45.1 \%$ in 2000 and reached $70.4 \%$ in 2017 due to consistent improvement in healthcare services for cancer patients [1]. The cancer patient experiences severe physical and psychological suffering as the illness progresses into terminal stage by worsening of the general condition. The most common symptoms in terminal cancer patients include pain, fatigue, anorexia, nausea, vomiting, constipation, delirium, and respiratory distress [2], and these symptoms alter their daily routine activities, ultimately impacting their quality of life in a negative way [3,4].

Recent meta-analysis research shows that more than one-third of cancer patients suffer from disturbance in ADL [5]. It is expected that terminal cancer patients with severe physical dysfunction may experience more severe alteration in daily activities. Activities of daily living (ADL) comprise six basic physical capacities essential for individuals to live independently: bathing, dressing, toileting, transferring, continence, and feeding [6], and act as a critical predictor of mortality and life expectancy of terminally-ill patients [7]. Losing the ability to perform ADL is one of the major stresses for terminally-ill patients [8] and may increase terminal patient's dependency on others and cause them to feel burdensome to their family, which may impose a sense of depression [9]. Such feelings of depression are the main cause of suicidal ideas in cancer patients [10]. Therefore, maintaining $A D L$ abilities is essential for terminal cancer patients to preserve independence and autonomy, which leads to improved quality of life and dignity at the end-of-life stage.

$A D L$ are correlated with diverse factors, including physiological factors, demographic factors, living arrangement, social support, exercise behavior, and participation in social activities [11-14]. Although ADL in cancer patients are a multi-dimensional outcome that is influenced by a variety of personal and inter-personal factors, they have been examined as a dependent variable with univariate relationships and individual factors in previous research without ample description of a cause-effect model. There is sparse research on structural equation modeling (SEM) of ADL in terminal cancer patients. Therefore, this study aims to develop a causal effect model of ADL in terminal cancer patients and to understand the causal relationships with predictors through SEM.

\section{Conceptual Framework}

This study used the International Classification of Functioning, Disability and Health (ICF), which was developed by World Health Organization, as a theoretical framework to explain ADL. The ICF framework classifies predictors into domains of personal factors, environmental factors, body functions and structure, activity and participation and emphasizes interactions among these factors to explain an individual's health status. [15]. The integrated model of ICF may be useful for understanding ADL and its 
influencing factors in terminal cancer patients from the standpoint of multi-dimensionality. In previous research, the ICF model has been used as a conceptual framework for explaining ADL in middle-aged adults [14] and community-dwelling elderly populations [13]. Based on the ICF model, this study built an ADL construct, and selected causal factors from previous studies and the perspectives of personal factors, environmental factors, body functions and structure, and activity. The participation domain in the ICF model was excluded from the ADL model in this study because it refers to social roles in a daily living context within the community, which may not be applicable to the mostly inpatients admitted in this study.

In the ICF model, personal factors are defined as individual characteristics influencing health status. In terms of personal factors, ADL have been reported to be significantly lower in patients with advanced age [13] and in women [16]. In previous studies, performance status and muscle volume, which can be indirect indicators of ADL in the elderly, are impacted by palliative chemotherapy [17]. Therefore, age, sex, and use of palliative chemotherapy were included as personal factors for predicting ADL in terminal cancer patients. In terms of the domain of environmental factors, older adults in long-term care facilities have been reported to have significantly lower ADL levels than community-dwelling older adults [18]. In accord with this finding, hospitalization was proposed as a causal independent variable for ADL in terminal cancer patients of this study. The activity factor in the ICF model includes engagement in specific activities or performance of tasks in a daily living context. Previous studies have reported that older adults both in long-term care facility and in the community show significant improvement in ADL when they engage in regular exercise [19]. Therefore, regular exercise was included as an independent variable, representing an activity factor in the ICF model, and predicts ADL in terminally-ill cancer patients in this study. Body functions and structure domain in the ICF model refer to physiological function and anatomical structure of the body. Previous studies have reported that pain [20] and fatigue [21] have negative impacts on ADL. Therefore, pain and fatigue were included as predictor variables for ADL, which were derived from the body functions and structure domain of the ICF model.

Based on review of the literature guided by the ICF model, 7 variables were included as predictors of ADL, and 20 pathways were proposed to explain the cause-effect model of ADL in terminally-ill patients. In the proposed structural equation model, age, gender, receipt of palliative chemotherapy, hospitalization, and regular exercise were proposed as causal variables. Pain and fatigue, which may be affected by personal and environmental factors [15], were included as mediating variables in the model.

\section{Methods}

\section{Study design}

This was a cross-sectional descriptive study. SEM was used to test the direct and indirect effects of physiological and psychological predictors on ADL in terminal cancer patients.

\section{Participants}

A total of 238 study participants were recruited from two hospitals located in Seoul metropolitan area, Korea. The sample size of this study was regarded as adequate for SEM, as the sample size of 200 or over is general accepted as recommended minimum size of sample for SEM research [22]. A convenience sampling method was used for recruiting study participants. Study participants were cancer patients who were aged 19 years or over, diagnosed as terminal cancer, and the recipient of palliative care at the time of data collection. Cancer patients of all stages of palliative care were recruited for participating in the study, including outpatients of oncology department, inpatients in a private clinic, and inpatients of hospice unit at a general hospital. Those who were able to communicate verbally, understand the purpose of the study and willing to participate in the research were included as the subjects.

\section{Procedure}

The data were collected from September 2013 to March 2016 using a structured questionnaire. After the IRB approval, eligible individuals were verbally invited to participate in the study, and those who signed informed consent completed a survey questionnaire. Researchers provided assistance with reading the questionnaire for participants who needed such help. It took about 20 minutes for a study participant to complete a survey questionnaire.

\section{Measurements}

Page $3 / 16$ 
All the measurements for this study were used upon the permit of original developers for the use of the scales.

\section{Demographic And Clinical Characteristics}

Demographic characteristics included age, gender, level of education, religion, main caregiver, and regular exercise behavior. Clinical characteristics included co-morbid disease, length of morbid period after cancer diagnosis, receiving of palliative chemotherapy, current hospitalization status.

\section{Pain}

Pain was measured using visual analogue scale (VAS). The intensity of pain was scored from 0 to 10 , in which 0 represents 'no pain at all' and 10 represents 'unbearable pain'. A higher score indicated more severe pain. The severity of pain was categorized into none (0), mild (1-4), moderate (5-6), or severe ( $\geq 7)[23]$.

\section{Fatigue}

Fatigue was measured using the Korean version Functional Assessment of Chronic Illness Therapy-Fatigue [24]. The scale consists of thirteen items to measure the level of fatigue during the last seven days, and each item is scored from 0 (not at all) to 4 (very likely). A total score ranges from 0 to 52 , and a lower score indicates more severe fatigue. For reduce confusion in interpretation of the results, a reverse coding was performed in the data analysis stage so that a higher score represents more severe level of fatigue. The Cronbach's alpha of the scale at the time of development was .95 [24]. The Cronbach's alpha for this study was .90 . Because the fatigue scale was uni-dimensional and may possibly reduce the mode fit, the scale was re-structured into three item parcels based on the guides by Russel at all (1988) [25]. The items of the scale were classified into three item parcels: fatigue 1 , fatigue 2 , and fatigue 3.

\section{Physical Function}

Physical function was measured using the Katz index of independence in ADL [6]. The scale consists of six domains of basic physical function, including bathing, dressing, toileting, transferring, continence, and feeding. Each item is scored from 0 to 2 , in which 0 indicating 'unable to do at all', 1 meaning 'able to do with some help', and 2 indicating 'able to do independently.' A maximum score is 12, and a higher score indicates a higher level of physical function. A score of 12 means no assistance is required, and a score of 11 or less means assistance is required. The Cronbach's alpha reliability of the scale was .98 in this study.

\section{Data analysis}

Demographic and clinical characteristics and study variables were analyzed using descriptive statistics. Internal consistency reliability of the measurements was examined using Cronbach's alpha. Normality of the data was assessed by skewness and kurtosis. Correlations and collinearity of measured variables were evaluated by Pearson's correlation coefficient. Structural equation model was analyzed using Maximum Likelihood estimation. Model fit and reliability and validity of the latent variable were examined by confirmatory factor analysis (CFA). Fit of the data to the hypothesized model was evaluated by fit indices, including Chi-square $\left(\chi^{2}\right)$, normal Chi-square ( $\left.\chi^{2} / d f\right)$, Goodness of Fit Index (GFI), Standardized Root Mean Square Residual (SRMR), Root Mean Square Error of Approximation (RMSEA), Comparative Fit Index (CFI), Normed Fit Index (NFI), and TuckerLewis Index. Bootstrapping method was used to examine statistical significance of direct effect, indirect effect, and total effect of the hypothesized model. Additional bootstrapping was performed after phantom variable, that does not affect model fit and population parameter, was identified in order to evaluate whether specific indirect effect among the variables was statistically significant. The data were analyzed using SPSS WIN 25.0 and AMOS 23.0 programs, and $p$ values $<0.05$ were considered statistically significant.

\section{Results}

\section{Demographic and clinical characteristics}


Of the study participants, $65.5 \%$ were aged 65 years or over, and $53.8 \%$ male. About one-third of the participants (35.3\%) was middle school graduates, and $76.9 \%$ reported participation in religion. Most participants (84.0\%) reported their main caregivers as family. Approximately $35 \%$ of the participants were engaged in exercise (20 minutes of walking or muscle strength training) at least three times a week. More than $40 \%$ of the participants (43.3\%) had one or more co-morbid diseases, and $45.8 \%$ of them suffered from illness one to three years after cancer diagnosis. Approximately $19 \%$ of the participants were receiving palliative chemotherapy, and $74.4 \%$ of them were hospitalized patients (Table 1 ).

Table 1

Participants' demographic and clinical characteristics $(N=238)$

\begin{tabular}{|ll|}
\hline Article title & $\begin{array}{l}\text { A structural equation modeling approach to understanding physical function of terminal cancer } \\
\text { patients }\end{array}$ \\
\hline Journal name & Supportive Care in Cancer \\
\hline Author names & Han-Gyo Choi, Hye-Ah Yeom, Myung Ah Lee, Jeong-Ran Ra \\
\hline $\begin{array}{l}\text { Corresponding } \\
\text { author }\end{array}$ & $\begin{array}{l}\text { Hye-Ah Yeom } \\
\text { Affiliation: College of Nursing, The Catholic University of Korea } \\
\text { E-mail address: yha@catholic.ac.kr }\end{array}$ \\
\hline
\end{tabular}

\section{Levels of fain, fatigue, and ADL}

Descriptive results of the measured variables are presented in Table 2. Levels of pain, fatigue, and ADL were somewhat high among the participants. Of the participants, $60.5 \%$ reported moderate or severe pain, and $63.0 \%$ had limitation in ADL. 
Table 2

Descriptive statistics of measured variables $(N=238)$

\begin{tabular}{|c|c|c|}
\hline Variables & Categories & $\mathrm{n}(\%)$ \\
\hline \multirow[t]{2}{*}{ Age (yr) } & $<65$ & $82(34.5)$ \\
\hline & $\geq 65$ & $156(65.5)$ \\
\hline \multirow[t]{2}{*}{ Gender } & Male & $128(53.8)$ \\
\hline & Female & $110(46.2)$ \\
\hline \multirow[t]{3}{*}{ Education level } & Under middle school & $84(35.3)$ \\
\hline & High school & $80(33.6)$ \\
\hline & College or higher & $74(31.1)$ \\
\hline \multirow[t]{2}{*}{ Religion } & Yes & $183(76.9)$ \\
\hline & No & $55(23.1)$ \\
\hline \multirow[t]{2}{*}{ Caregiver } & Family & $200(84.0)$ \\
\hline & Others or none & $38(16.0)$ \\
\hline \multirow[t]{2}{*}{ Regular exercise } & Yes & $82(34.5)$ \\
\hline & No & $156(65.5)$ \\
\hline \multirow[t]{2}{*}{ Comorbidity } & Yes & $103(43.3)$ \\
\hline & No & $135(56.7)$ \\
\hline \multirow[t]{4}{*}{ Duration since diagnosis (month) } & $<12$ & $26(10.9)$ \\
\hline & $12 \sim 35$ & $109(45.8)$ \\
\hline & $\geq 36$ & $95(39.9)$ \\
\hline & Unknown & $8(3.4)$ \\
\hline \multirow[t]{2}{*}{ Palliative chemotherapy use } & Yes & $46(19.3)$ \\
\hline & No & $192(80.7)$ \\
\hline \multirow[t]{2}{*}{ Care setting } & Outpatient setting & $61(25.6)$ \\
\hline & Inpatient setting & $177(74.4)$ \\
\hline
\end{tabular}

\section{Normality and multi-collinearity of measured variables}

Analysis of skewness and kurtosis of the variables showed that skewness ranged from -0.75 to -0.18 and kurtosis ranged from -1.34 to -0.70 , meeting the recommended normal distribution criteria of skewness less than 2 and kurtosis less than 7 in absolute value [26]. The largest correlation matrix between variables was 0.51 , which did not exceed 0.8 , the criterion for multicollinearity [27], so there was no problem of multi-collinearity.

\section{Model fit of the hypothesized model}

\section{Confirmatory Factor Analysis Of Measured Variables}

To evaluate validity of constructs, confirmatory factor analysis was performed on the latent variables of fatigue and ADL. The analysis was conducted based on the fact that a variable is regarded as significant if standard factor loading (SFL) of the variable is over 0.4 in an absolute value [28]. In this study, SFL of fatigue $(0.86 \sim 0.95)$ and ADL $(0.83 \sim 0.99)$ met the recommended criteria. Construct reliability was 0.99 for fatigue and 0.91 for $A D L$, meeting the recommended criteria of 0.7 or over. There was no issue in convergent validity, as average variance extracted (AVE) was 0.92 for fatigue and 0.78 for ADL, 
meeting the recommended criteria of 0.5 or over [29]. Comparison of AVE with squared correlations in fatigue and ADL showed that AVE was larger than the squared correlation indices, demonstrating the discriminant validity of the variables [29].

\section{Model Fit Of The Hypothesized Model}

A model fit is considered as reasonable with Chi-square value of over 0.5 , normed Chi-square values of less than, RMSEA of less than 0.08 , AGFI of over 0.85 , along with values over $0.90 \mathrm{in} \mathrm{GFI,} \mathrm{NFI,} \mathrm{TLI,} \mathrm{and} \mathrm{CFI.} \mathrm{The} \mathrm{hypothetical} \mathrm{model} \mathrm{showed} \mathrm{a} \mathrm{good} \mathrm{fit} \mathrm{to} \mathrm{the}$ data $\left(\mathrm{X}^{2} / \mathrm{df}=2.08, \mathrm{GFI}=0.932, \mathrm{NFI}=0.966, \mathrm{TLI}=0.971, \mathrm{CFI}=0.982, \mathrm{AGFI}=0.874, \mathrm{RMSEA}=0.067\right)$. Although Chi-square index was $134.98(<0.001)$, overall fit of the model was regarded as adequate in the consideration of the fact that Chi-square statistics are overly sensitive to sample size and is less commonly used [30].

\section{Path Analysis For The Hypothesized Model}

Direct effect, indirect effect, and total effect were tested on latent variables of the hypothesized model. Analysis of the pathways showed that 9 of 18 pathways were statistically significant (Table 3, Fig. 1). There were significant direct effects of receipt of palliative chemotherapy $(B=-0.28, p=0.006)$, hospitalization $(B=0.35, p=0.012)$, and regular exercise behavior $(B=-0.15, p=0.011)$ on pain.

Table 3

Standardized direct, indirect, and total effects for the hypothesized model $(N=238)$

\begin{tabular}{|c|c|c|c|c|c|c|}
\hline & Possible Range & Min & Max & $\begin{array}{l}\text { Mean } \pm \text { SD or } \\
\mathrm{n}(\%)\end{array}$ & Skewness & Kurtosis \\
\hline Fatigue & $0 \sim 52$ & 0 & 51 & $29.28 \pm 13.00$ & -0.58 & -0.81 \\
\hline Pain & $0 \sim 10$ & 1 & 10 & $5.32 \pm 3.03$ & -0.18 & -1.34 \\
\hline none (0) & & & & $0(0.0)$ & & \\
\hline mild $(1-4)$ & & & & $94(39.5)$ & & \\
\hline moderate $(5-6)$ & & & & $37(15.5)$ & & \\
\hline severe $(\geq 7)$ & & & & $107(45.0)$ & & \\
\hline ADL & $0 \sim 12$ & 0 & 12 & $8.07 \pm 4.24$ & -0.75 & -0.70 \\
\hline requiring assistance $(0-11)$ & & & & $150(63.0)$ & & \\
\hline requiring no assistance (12) & & & & $88(37.0)$ & & \\
\hline
\end{tabular}

In terms of fatigue, palliative chemotherapy had significant indirect effect $(B=-0.05, p=0.007)$ on fatigue. Hospitalization had both direct effect $(B=0.22, p=0.037)$ and indirect effect $(B=0.07, p=0.010)$ on fatigue. Regular exercise behavior had significant direct effect $(B=-0.32, p=0.001)$ and indirect effect $(B=-0.03, p=0.012)$ on fatigue. Pain had significant direct effect $(B=0.19, p=$ $0.009)$ on fatigue.

Hospitalization had direct effect $(B=-0.29, p=0.001)$ on $A D L$. Regular exercise behavior had direct effect $(B=0.23, p=0.001)$ and indirect effect $(B=0.08, p=0.003)$ on $A D L$. Pain had indirect effect $(B=-0.04, p=0.008)$ on ADL. Fatigue had direct effect $(B=-0.24$, $p=0.005)$ on $A D L$. The factors that had an influence on ADL were hospitalization $(\beta=-0.35)$, regular exercise $(\beta=0.31)$, and fatigue $(\beta=-0.24)$ explaining $35.1 \%$ of the variance.

Figure 1 Path diagram for the structural equation model on physical function in terminal cancer patients ${ }^{\star} p<0.05$; ${ }^{* \star} p<0.01$; ${ }^{* \star} p$ $<0.001 ; y 1$, fatigue $1 ; y 2$, fatigue $2 ; y 3$, fatigue $3 ; y 4$, bathing; $y 5$, dressing; $y 6$, toileting; $y 7$, transferring; $y 8$, continence; y9, feeding

\section{Mediating Effect In Hypothesized Model}


The mediating effects of pain and fatigue in the relationships between independent variables (age, gender, palliative chemotherapy, hospitalization, and regular exercise) and ADL were examined. Five of fifteen pathways that include pain or fatigue as mediating variable were statistically significant. These pathways include: Palliative chemotherapy $\rightarrow$ Pain $\rightarrow$ Fatigue $\rightarrow \mathrm{ADL}(\mathrm{B}=0.02, p=0.006)$, Hospitalization $\rightarrow$ Fatigue $\rightarrow \mathrm{ADL}(\mathrm{B}=-0.08, p=0.025)$, Hospitalization $\rightarrow$ Pain $\rightarrow$ Fatigue $\rightarrow$ ADL $(B=-0.02, p=0.008)$, Regular exercise $\rightarrow$ Fatigue $\rightarrow A D L(B=0.10, p=0.003)$, and Regular exercise $\rightarrow$ Pain $\rightarrow$ Fatigue $\rightarrow A D L(B=$ $0.01, p=0.009$ ) (Table 4). 
Table 4

Specific indirect effect for the hypothesized model

\begin{tabular}{|c|c|c|c|c|c|c|c|c|}
\hline \multirow[t]{2}{*}{ Path } & \multirow[t]{2}{*}{ B } & & \multicolumn{2}{|l|}{ SE } & \multicolumn{2}{|l|}{$p$} & \multicolumn{2}{|l|}{$95 \% \mathrm{Cl}$} \\
\hline & & & & & & & $\begin{array}{l}\text { Lower } \\
\text { bounds }\end{array}$ & $\begin{array}{l}\text { Upper } \\
\text { bounds }\end{array}$ \\
\hline \multirow[t]{2}{*}{$\begin{array}{l}\text { Endogenous } \\
\text { variables }\end{array}$} & \multirow[t]{2}{*}{$\begin{array}{l}\text { Exogenous } \\
\text { variables }\end{array}$} & \multirow[t]{2}{*}{$\begin{array}{l}\text { Critical } \\
\text { ratio } \\
(p)\end{array}$} & \multirow[t]{2}{*}{ SMC } & $\begin{array}{l}\text { Standardized } \\
\text { direct effect }\end{array}$ & $\begin{array}{l}\text { Standardized } \\
\text { indirect } \\
\text { effect }\end{array}$ & $\begin{array}{l}\text { Standardized } \\
\text { total effect }\end{array}$ & & \\
\hline & & & & $\beta(p)$ & $\beta(p)$ & $\beta(p)$ & & \\
\hline \multirow[t]{5}{*}{ Pain } & Age & $\begin{array}{l}0.31 \\
(0.754)\end{array}$ & 0.430 & $\begin{array}{l}0.016 \\
(0.785)\end{array}$ & & $\begin{array}{l}0.016 \\
(0.785)\end{array}$ & & \\
\hline & $\begin{array}{l}\text { Gender } \\
\text { (female) }\end{array}$ & $\begin{array}{l}-1.07 \\
(0.285)\end{array}$ & & $\begin{array}{l}-0.054 \\
(0.309)\end{array}$ & & $\begin{array}{l}-0.054 \\
(0.309)\end{array}$ & & \\
\hline & $\begin{array}{l}\text { Palliative } \\
\text { chemotherapy }\end{array}$ & $\begin{array}{l}-3.08 \\
(0.002)\end{array}$ & & $\begin{array}{l}-0.275 \\
(0.006)\end{array}$ & & $\begin{array}{l}-0.275 \\
(0.006)\end{array}$ & & \\
\hline & Hospitalization & $\begin{array}{l}3.75(< \\
0.001)\end{array}$ & & $\begin{array}{l}0.346 \\
(0.012)\end{array}$ & & $\begin{array}{l}0.346 \\
(0.012)\end{array}$ & & \\
\hline & $\begin{array}{l}\text { Regular } \\
\text { exercise }\end{array}$ & $\begin{array}{l}-2.70 \\
(0.007)\end{array}$ & & $\begin{array}{l}-0.146 \\
(0.011)\end{array}$ & & $\begin{array}{l}-0.146 \\
(0.011)\end{array}$ & & \\
\hline \multirow[t]{6}{*}{ Fatigue } & Age & $\begin{array}{l}-0.50 \\
(0.619)\end{array}$ & 0.477 & $\begin{array}{l}-0.026 \\
(0.744)\end{array}$ & $\begin{array}{l}0.003 \\
(0.732)\end{array}$ & $\begin{array}{l}-0.022 \\
(0.773)\end{array}$ & & \\
\hline & $\begin{array}{l}\text { Gender } \\
\text { (female) }\end{array}$ & $\begin{array}{l}0.44 \\
(0.663)\end{array}$ & & $\begin{array}{l}0.022 \\
(0.629)\end{array}$ & $\begin{array}{l}-0.010 \\
(0.235)\end{array}$ & $\begin{array}{l}0.012 \\
(0.780)\end{array}$ & & \\
\hline & $\begin{array}{l}\text { Palliative } \\
\text { chemotherapy }\end{array}$ & $\begin{array}{l}-1.34 \\
(0.182)\end{array}$ & & $\begin{array}{l}-0.122 \\
(0.230)\end{array}$ & $-0.052(.007)$ & $\begin{array}{l}-0.174 \\
(0.970)\end{array}$ & & \\
\hline & Hospitalization & $\begin{array}{l}2.32 \\
(0.021)\end{array}$ & & $\begin{array}{l}0.221 \\
(0.037)\end{array}$ & $\begin{array}{l}0.065 \\
(0.010)\end{array}$ & $\begin{array}{l}0.286 \\
(0.007)\end{array}$ & & \\
\hline & $\begin{array}{l}\text { Regular } \\
\text { exercise }\end{array}$ & $\begin{array}{l}-5.68 \\
(< \\
0.001)\end{array}$ & & $\begin{array}{l}-0.322 \\
(0.001)\end{array}$ & $\begin{array}{l}-0.028 \\
(0.012)\end{array}$ & $\begin{array}{l}-0.349 \\
(0.001)\end{array}$ & & \\
\hline & Pain & $\begin{array}{l}2.90 \\
(0.004)\end{array}$ & & $\begin{array}{l}0.189 \\
(0.009)\end{array}$ & & $\begin{array}{l}0.189 \\
(0.009)\end{array}$ & & \\
\hline \multirow[t]{7}{*}{ ADL } & Age & $\begin{array}{l}0.69 \\
(0.488)\end{array}$ & 0.351 & $\begin{array}{l}0.038 \\
(0.571)\end{array}$ & $\begin{array}{l}0.006 \\
(0.633)\end{array}$ & $\begin{array}{l}0.044 \\
(0.550)\end{array}$ & & \\
\hline & $\begin{array}{l}\text { Gender } \\
\text { (female) }\end{array}$ & $\begin{array}{l}-0.61 \\
(0.544)\end{array}$ & & $\begin{array}{l}-0.033 \\
(0.594)\end{array}$ & $\begin{array}{l}-0.004 \\
(0.631)\end{array}$ & $\begin{array}{l}-0.037 \\
(0.506)\end{array}$ & & \\
\hline & $\begin{array}{l}\text { Palliative } \\
\text { chemotherapy }\end{array}$ & $\begin{array}{l}-0.50 \\
(0.615)\end{array}$ & & $\begin{array}{l}-0.049 \\
(0.303)\end{array}$ & $\begin{array}{l}0.034 \\
(0.249)\end{array}$ & $\begin{array}{l}-0.015 \\
(0.627)\end{array}$ & & \\
\hline & Hospitalization & $\begin{array}{l}-2.78 \\
(0.006)\end{array}$ & & $\begin{array}{l}-0.289 \\
(0.001)\end{array}$ & $\begin{array}{l}-0.059 \\
(0.094)\end{array}$ & $\begin{array}{l}-0.348 \\
(0.001)\end{array}$ & & \\
\hline & $\begin{array}{l}\text { Regular } \\
\text { exercise }\end{array}$ & $\begin{array}{l}3.60(< \\
0.001)\end{array}$ & & $\begin{array}{l}0.234 \\
(0.001)\end{array}$ & $\begin{array}{l}0.078 \\
(0.003)\end{array}$ & $\begin{array}{l}0.312 \\
(0.001)\end{array}$ & & \\
\hline & Pain & $\begin{array}{l}0.35 \\
(0.729)\end{array}$ & & $\begin{array}{l}0.025 \\
(0.759)\end{array}$ & $\begin{array}{l}-0.044 \\
(0.008)\end{array}$ & $\begin{array}{l}-0.020 \\
(0.808)\end{array}$ & & \\
\hline & Fatigue & $\begin{array}{l}-3.04 \\
(0.002)\end{array}$ & & $\begin{array}{l}-0.235 \\
(0.005)\end{array}$ & & $\begin{array}{l}-0.235 \\
(0.005)\end{array}$ & & \\
\hline $\begin{array}{l}\text { Age } \rightarrow \text { Pain } \rightarrow \\
\text { ADL }\end{array}$ & 0.000 & & 0.000 & 0.608 & & 0.000 & & 0.001 \\
\hline
\end{tabular}




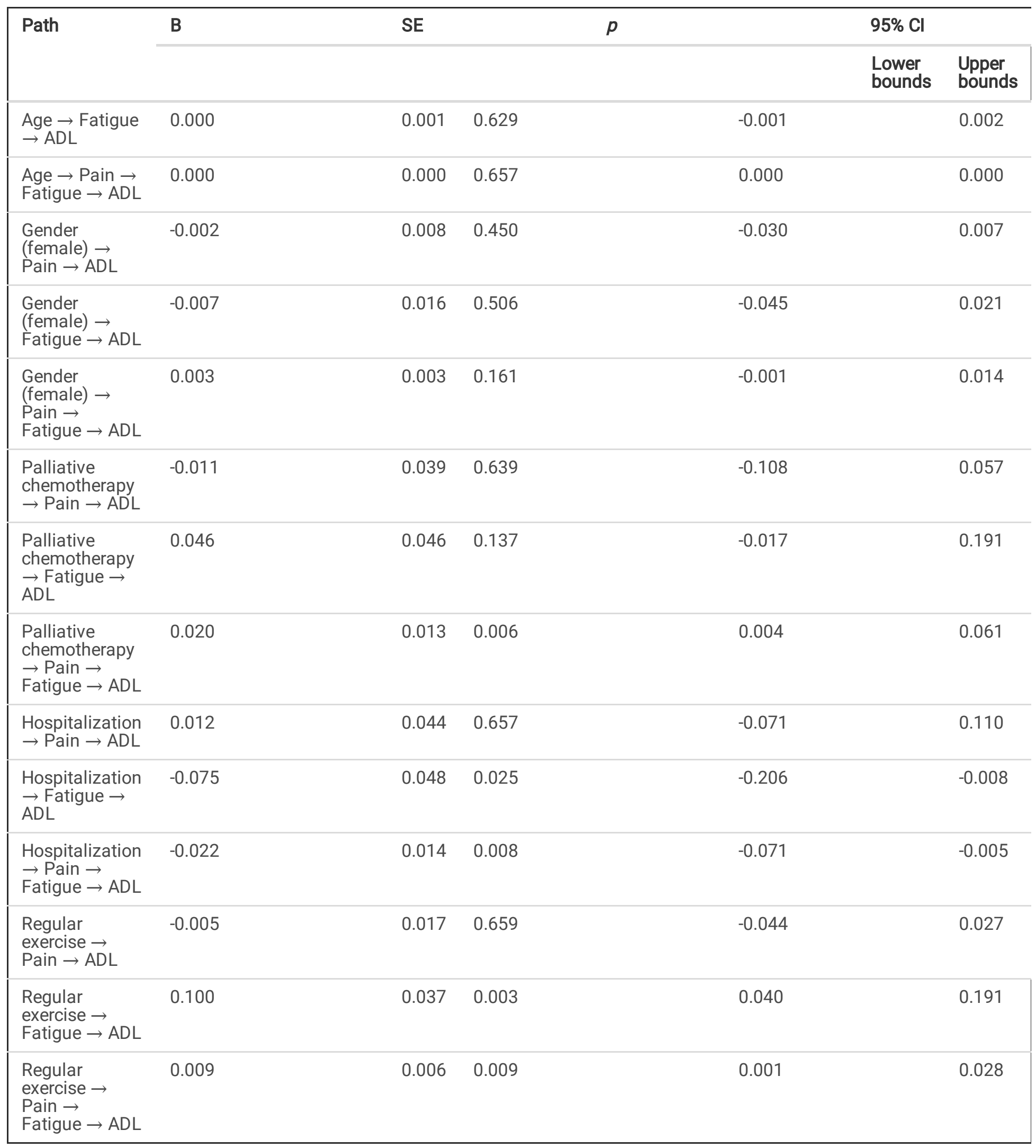

\section{Discussion}

This study proposed a hypothetical model of ADL in terminal cancer patients, and tested the model through SEM to identify factors influencing ADL. It was found that $63 \%$ of the study participants had limitation in ADL, which is higher than $37 \%$ of adult 
cancer patients [5] and $48 \%$ of patients with metastatic cancer [31], suggesting that ADL limitation in terminal cancer patients is more severe than in other groups.

The hypothetical model proposed in this study showed sound fit to the data, implying that the model is an adequate framework to explain ADL in terminal cancer patients. In the model, age and sex did not have any effect on $A D L$, which is inconsistent with the findings of previous studies suggesting that older age [32] and women [14] predicted ADL limitation. It is plausible that the disease severity of the terminal cancer patients in the present study was high, reducing the influence of personal factors on ADL. The ADL of terminal cancer patients was predicted by interactions among personal factors, environmental factors, body functions and structure and activity explaining $35.1 \%$ of the variance. ADL was positively influenced by regular exercise and negatively influenced by hospitalization, fatigue, and pain.

The most influential factor that predicts ADL in terminal cancer patients was hospitalization. This result suggests that admission itself can affect the daily routine and physical function of the cancer patient but may also imply that a decrease of ADL level due to worsened health status can be a triggering factor for hospitalization. It has been reported that $33 \%$ of older women with functional limitation experience reduced physical function after admission to a hospital. Further, extended length of admission increases the risk (1.69 times) of reduction in physical function [33], supporting the findings of this study. Hospitalizationassociated disability, defined as worsening of ADL limitation at the time of hospital discharge compared to that at admission, occurs in one-third of inpatients older than 70 years [34]. An inpatient with terminal cancer tends to spend most of the time in bed during the admission period, which may result in reduced levels of physical activity [35] and muscle volume and function [36], leading to increased disability. Therefore, it is necessary for healthcare providers to regularly assess the patient's physical function and motivate the patient to engage in physical activity.

The second most significant predictor of ADL in terminal cancer patients was regular exercise. Regular exercise is known to improve mobility in terminal cancer patients [37]. Specifically for frail elderly patients, regular exercise enhances ADL levels [19]. In this study, regular exercise improved participants' ADL level directly and indirectly either by reducing fatigue or decreasing fatigue through controlling pain. This finding is in line with reports that regular exercise decreases cancer-related fatigue [38] and pain [39] and improves physical function [39]. Therefore, engagement in regular exercise is important for patients even in a terminal cancer stage to relieve pain and fatigue and to maintain maximal physical function. However, the intensity of exercise needs to be controlled based on the patient's physical condition, while considering that the physical and cognitive status of the terminal cancer patient may change rapidly [40].

In this study, fatigue was the third most influential factor on ADL of terminal cancer patients, followed by hospitalization and regular exercise. The significant impact of fatigue on physical function is consistent with the findings of previous research demonstrating that fatigue reduces the physical performance of cancer patients [21]. Fatigue is one of the most critical factors that affect quality of life in terminal cancer patients [4] and is an indicator of remaining life expectancy [41]. However, fatigue of cancer patients is less recognized by healthcare providers than are more urgent symptoms [42]. Cancer patients tend not to complain about fatigue to healthcare providers due to the impression that it is not an important symptom or fear that talking about fatigue may hinder healthcare providers solely focusing on treatment of cancer illness [43]. Therefore, healthcare providers should encourage cancer patients to describe their symptoms in detail, including fatigue. It is also important to identify and correct underlying conditions leading to fatigue.

In this study, pain did not affect ADL directly but decreased ADL level indirectly through fatigue as a mediator. This finding is consistent with that of a previous view that pain impacts functional performance of cancer patients through fatigue as a mediating factor [44]. $60.5 \%$ of the subjects in this study experienced moderate or severe level of pain, suggesting that pain is a major symptom in terminal cancer patients and may affect their quality of life [45]. Therefore, it is necessary for healthcare providers actively manage pain in order to improve ADL as well as quality of life in terminal cancer patients.

This study is significant in that it provides an integrated perspective on the factors affecting ADL in terminal cancer patients through a multidimensional approach. However, in this study, it is difficult to generalize the results by using the convenient sampling method when selecting subjects, so further studies need to be repeated for terminal cancer patients in various regions.

Page $11 / 16$ 
Also, since this study collected data based on a self-reported questionnaire, there was a limit to securing objectivity. Therefore, it is proposed to use objective clinical variables in future studies.

\section{Conclusion}

The SEM of this study showed significant pathways among factors influencing ADL of terminal cancer patients. ADL was positively influenced by regular exercise and was negatively influenced by hospitalization, fatigue, and pain. Based on these results, in order to minimizing the problems of physical function in terminal cancer patients, interventions that reduce pain and fatigue and provide regular exercise are required. Particularly, hospitalized patients are susceptible to a decrease in ADL, so regular physical function evaluations may be considered.

\section{Declarations}

Funding: This work was supported by the Catholic Medical Center Research Foundation made in the program year of 2019 (No. 52019B00010016) and the National Research Foundation of Korea (NRF) grant funded by the Korea government (Ministry of Science and ICT) (No. NRF-2017R1A2B1010413).

Conflicts of interest: The authors declare that they have no conflict of interest.

Ethics approval: Approval was obtained from the ethic committee of the Catholic University of Korea and the Seoul St. Mari's hospital.

Consent to participate: Informed consent was obtained from all individual participants included in the study.

Consent for publication: N/A.

Availability of data and material: The data are not publicly available due to restrictions of IRB policy.

Code availability: N/A.

Authors' contributions: Conception / Design: Han-Gyo Choi, Hye-Ah Yeom; Funding acquisition: Hye-Ah Yeom; Data collection: Hye-Ah Yeom, Myung Ah Lee, Jeong-Ran Ra; Data analysis and Interpretation: Han-Gyo Choi, Hye-Ah Yeom; Manuscript writing: All authors; Final approval of manuscript: All authors.

\section{References}

1. Statistics Korea (2017) Cancer incident cases and incidence rates by site (24 items), sex, age group.

http://kosis.kr/statisticsList/statisticsListlndex.do?

menuld=M_01_01\&vwcd=MT_ZTITLE\&parmTabld=M_01_01\#SelectStatsBoxDiv. Accessed 14 May 2020

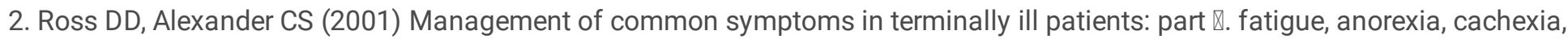
nausea and vomiting. Am Fam Physician 64(5):807-814

3. Mikan F, Wada M, Yamada M, Takahashi A, Onishi H, Ishida M, Sato K, Shimizu S, Matoba M, Miyashita M (2016) The association between pain and quality of life for patients with cancer in an outpatient clinic, an inpatient oncology ward, and inpatient palliative care units. Am J Hosp Palliat Care 33(8):782-790. https://doi.org/10.1177/1049909116630266

4. Kwon YC, Yun YH, Lee KH, Son KY, Park SM, Chang YJ, Wang XS, Mendoza TR, Cleeland CS (2006) Symptoms in the lives of terminal cancer patients: which is the most important? Oncology 71:69-76. https://doi.org/10.1159/000100450

5. Neo J, Fettes L, Gao W, Higginson IJ, Maddocks M (2017) Disability in activities of daily living among adults with cancer: a systematic review and meta-analysis. Cancer Treat Rev 61:94-106. https://doi.org/10.1016/j.ctrv.2017.10.006 
6. Katz S, Ford AB, Moskowitz RW, Jackson BA, Jaffe MW (1963) Studies of illness in the aged. the index of ADL: a standardized measure of biological and psychological function. JAMA 185:914-918. https://doi.org/10.1001/jama.1963.03060120024016

7. Park HS, Lee KT, Kim TW (2017) Role of physical activity in mortality prediction in elderly hospice patients. J Exerc Rehabil 13(2):250-254. https://doi.org/10.12965/jer.1734950.475

8. Eva G, Wee B (2010) Rehabilitation in end-of-life management. Curr Opin Support Palliat Care 4:158-162. https://doi.org/10.1097/SPC.0b013e32833add27

9. Xie H, Peng W, Yang Y, Zhang D, Sun Y, Wu M, Zhang J, Jia J, Su Y (2018) Social support as a mediator of physical disability and depressive symptoms in Chinese elderly. Arch Psychiatr Nurs 32(2):256-262. https://doi.org/10.1016/j.apnu.2017.11.012

10. O'Mahony S, Goulet J, Kornblith A, Abbatiello G, Clarke B, Kless-Siegel S, Breitbart W, Payne R (2005) Desire for hastened death, cancer pain and depression: report of a longitudinal observational study. J Pain Symptom Manage 29(5): 446-457. https://doi.org/10.1016/j.jpainsymman.2004.08.010

11. Luciani A, Jacobsen PB, Extermann M, Foa P, Marussi D, Overcash JA, Balducci L. Fatigue and functional dependence in older cancer patients. Am J Clin Oncol 31(5):424-430. https://doi.org/10.1097/coc.ob013e31816d915f

12. Talaei-Khoei M, Ogink PT, Jha R, Ring D, Chen N, Vranceanu AM (2017) Cognitive intrusion of pain and catastrophic thinking independently explain interference of pain in the activities of daily living. J Psychiatr Res 91:156-163.

https://doi.org/10.1016/j.jpsychires.2017.04.005

13. Park YK, Suh SR (2018) A predictive model of instrumental activities of daily living in community-dwelling elderly based on ICF model. The Journal of the Korea Contents Association 18(2):113-123. https://doi.org/10.5392/JKCA.2018.18.02.113

14. den Ouden MEM, Schuurmans MJ, Mueller-Schotte S, Brand JS, van der Schouw YT (2013) Domains contributing to disability in activities of daily living. J Am Med Dir Assoc 14(1):18-24. https://doi.org/10.1016/j.jamda.2012.08.014

15. World Health Organization (2001) The international classification of functioning, disability and health-ICF. http://www.who.int/classifications/icf/en/. Accessed 22 April 2020

16. Ohta Y, Nomura E, Hatanaka N, Osakada Y, Matsumoto N, Sasaki R, Tsunoda K, Takemoto M, Tadokoro K, Hishikawa N, Wakutani Y, Yamashita T, Sato K, Omote Y, Abe K (2019) Female dominant association of sarcopenia and physical frailty in mild cognitive impairment and Alzheimer's disease. J Clin Neurosci 70:96-101. https://doi.org/10.1016/j.jocn.2019.08.062

17. Stene GB, Helbostad JL, Amundsen T, Sørhaug S, Hjelde H, Kaasa S, Grønberg BH. (2015) Changes in skeletal muscle mass during palliative chemotherapy in patients with advanced lung cancer. Acta Oncol 54(3):340-348.

doi:10.3109/0284186X.2014.953259

18. So H, Kim H, Ju K. (2011) Prediction model of quality of life in elderly based on ICF model. J Korean Acad Nurs 41(4):481-490. http://dx.doi.org/10.4040/jkan.2011.41.4.481

19. Sato D, Kaneda K, Wakabayashi H, Nomura T (2007) The water exercise improves health-related quality of life of frail elderly people at day service facility. Qual Life Res 16:1577-1585. https://doi.org/10.1007/s11136-007-9269-2

20. Björk S, Juthberg C, Lindkvist M, Wimo A, Sandman PO, Winblad B, Edvardsson D (2016) Exploring the prevalence and variance of cognitive impairment, pain, neuropsychiatric symptoms and $A D L$ dependency among persons living in nursing homes; a cross-sectional study. BMC Geriatr 16:154. https://doi.org/10.1186/s12877-016-0328-9

21. Jones JM, Olson K, Catton P, Catton CN, Fleshner NE, Krzyzanowska MK, McCready DR, Wong RKS, Jiang H, Howell D (2016) Cancer-related fatigue and associated disability in post-treatment cancer survivors. J Cancer Surviv 10(1):51-61.

https://doi.org/10.1007/s11764-015-0450-2

Page $13 / 16$ 
22. Hair JF Jr, Black WC, Babin BJ, Anderson RE (2018) Multivariate Data Analysis. CENGAGE, Boston

23. Serlin RC, Mendoza TR, Nakamura Y, Edwards KR, Cleeland CS (1995) When is cancer pain mild, moderate or severe? grading pain severity by its interference with function. Pain 61(2):277-284. https://doi.org/10.1016/0304-3959(94)00178-H

24. Cella D. Lai JS, Chang CH, Peterman A, Slavin M (2002) Fatigue in cancer patients compared with fatigue in the general United States population. Cancer 94(2):528-38. https://doi.org/10.1002/cncr.10245

25. Russell DW, Kahn JH, Spoth R, Altmaier EM (1998) Analyzing data from experimental studies: a latent variable structural equation modeling approach. J Couns Psychol 45(1):18-29. https://doi.org/10.1037/0022-0167.45.1.18

26. West SG, Finch JF, Curran PJ (1995) Structural equation models with nonnormal variables: problems and remedies. In: Hoyle RH (ed) Structural equation modeling: concepts, issues, and applications. Sage Publications, Thousand Oaks, pp 56-75

27. Lee EO, Im NT, Park HA, Lee IS, Kim JI, Bae JI, Lee SM (2009) Nursing research and statistical analysis. Soomoonsa, Seoul

28. Kim GS (2010) Analysis structural equation modeling. Hannarae Publishing Co., Seoul

29. Lee H, Lim J (2017) Structural equation modeling with AMOS 24. JypHyunJae Publishing Co., Seoul

30. Hooper D, Coughlan J, Mullen M (2007) Structural equation modelling: guidelines for determining model fit. Electronic Journal of Business Research Methods 6(1):53-60. https://doi.org/10.21427/D7CF7R

31. Johnsen AT, Petersen MA, Pedersen L, Groenvold M (2009) Symptoms and problems in a nationally representative sample of advanced cancer patients. Palliat Med 23(6):491-501. https://doi.org/10.1177/0269216309105400

32. Fujiwara Y, Yoshida H, Amano H, Fukaya T, Liang J, Uchida H, Shinkai S (2008) Predictors of improvement of decline in instrumental activities of daily living among community-dwelling older Japanese. Gerontology 54(6):373-380. https://doi.org/10.1159/000151221

33. Boyd CM, Ricks M, Fried LP, Guralnik JM, Xue QL, Xia J, Bandeen-Roche K (2009) Functional decline and recovery of activities

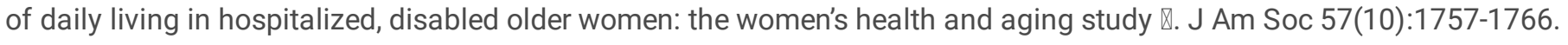
https://doi.org/10.1111/j.1532-5415.2009.02455.x

34. Covinsky KE, Pierluissi E, Johnston CB (2011) Hospitalization-associated disability: "She was probably able to ambulate, but I'm not sure". JAMA 306(16):1782-1793. https://doi.org/10.1001/jama.2011.1556

35. Wanigatunga AA, Gill TM, Marsh AP, Hsu FC, Yaghjyan L, Woods AJ, Glynn NW, King AC, Newton RL Jr, Fielding RA, Pahor M, Manini TM; Lifestyles intervention and independence for elders study investigators (2019) Effect of hospitalizations on physical activity patterns in mobility-limited older adults. J Am Geriatr Soc 67(2):261-268. https://doi.org/10.1111/jgs.15631

36. Kortebein P, Ferrando A, Lombeida J, Wolfe R, Evans WJ (2007) Effect of 10 days of bed rest on skeletal muscle in healthy older adults. JAMA 297(16):1772-1774. https://doi.org/10.1001/jama.297.16.1772-b

37. Oldervoll LM, Loge JH, Lydersen S, Paltiel H, Asp MB, Nygaard UV, Oredalen E, Frantzen TL, Lesteberg I, Amundsen L, Hjermstad MJ, Haugen DF, Paulsen $\emptyset$, Kaasa S (2011) Physical exercise for cancer patients with advanced disease: a randomized controlled trial. Oncologists 16(11):1649-1657. https://doi.org/10.1634/theoncologist.2011-0133

38. Tian L, Lu HJ, Lin L, Hu Y (2016) Effects of aerobic exercise on cancer-related fatigue: a meta-analysis of randomized controlled trials. Support Care Cancer 24(2):969-983. https://doi.org/10.1007/s00520-015-2953-9

39. Mustian KM, Sprod LK, Janelsins M, Peppone LJ, Mohile S (2013) Exercise recommendations for cancer-related fatigue, cognitive impairment, sleep problems, depression, pain, anxiety, and physical dysfunction: a review. Oncol Hematol Rev 8(2):8188. https://doi.org/10.17925/ohr.2012.08.2.81

Page $14 / 16$ 
40. Elmqvist MA, Jordhøy MS, Bjordal K, Kaasa S, Jannert M (2009) Health-related quality of life during the last three months of life in patients with advanced cancer. Support Care Cancer 17: 191-198. https://doi.org/10.1007/s00520-008-0477-2

41. Hwang SS, Chang VT, Cogswell J, Kasimis BS (2002) Clinical relevance of fatigue levels in cancer patients at a veterans administration medical center. Cancer 94(9):2481-2489. https://doi.org/10.1002/cncr.10507

42. Williams LA, Bohac C, Hunter S, Cella D (2016) Patient and health care provider perceptions of cancer-related fatigue and pain. Support Care Cancer 24(10):4357-4363. https://doi.org/10.1007/s00520-016-3275-2

43. Ripamonti Cl, Antonuzzo A, Bossi P, Cavalieri S, Roila F, Fatigoni S (2018) Fatigue, a major still underestimated issue. Curr Opin Oncol 30(4):219-225. https://doi.org/10.1097/CC0.0000000000000451

44. Oh HS, Seo YM, Jeong HS, Seo WS (2012) The identification of multiple symptom clusters and their effects on functional performance in cancer patients. J Clin Nurs 21(19-20):2832-2842. https://doi.org/10.1111/j.1365-2702.2011.04057.x

45. Oh SY, Shin SW, Koh SJ, Bae SB, Chang H, Kim JH, Kim HJ, Hong YS et al. (2017) Multicenter, cross-sectional observational study of the impact of neuropathic pain on quality of life in cancer patients. Support Care Cancer 25(12):3759-3767. https://doi.org/10.1007/s00520-017-3806-5

\section{Figures}

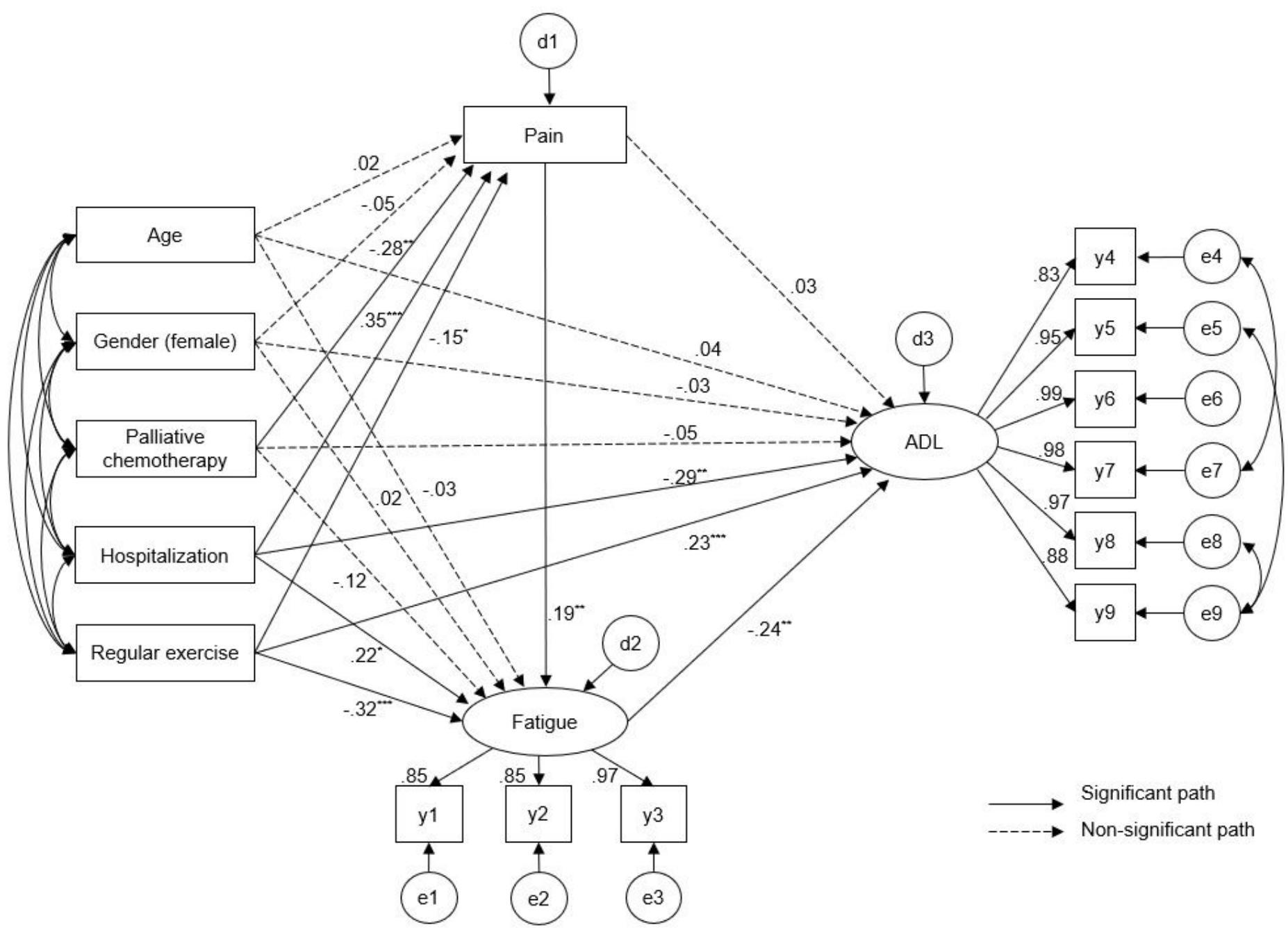




\section{Figure 1}

Path diagram for the structural equation model on physical function in terminal cancer patients ${ }^{*} p<0.05 ;{ }^{* \star} p<0.01$; ${ }^{* \star *} \mathrm{p}<0.001$; $y 1$, fatigue $1 ; y 2$, fatigue $2 ; y 3$, fatigue $3 ; y 4$, bathing; $y 5$, dressing; $y 6$, toileting; $y 7$, transferring; $y 8$, continence; $y 9$, feeding 